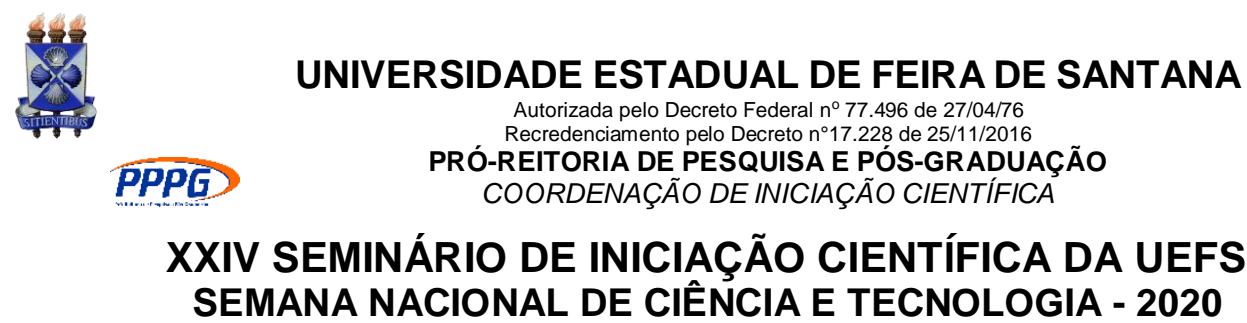

\title{
A historiografia em História da Educação nos Cursos de História na Bahia: apontamentos iniciais sobre um Estado da Arte.
}

\author{
Primeiro Autor ${ }^{1}$; Segundo Autor ${ }^{2}$ \\ 1. Rebeca Laíse Santos Lima PROBIC/UEFS, Graduando em Licenciatura em História, Universidade Estadual de Feira de Santana, \\ e-mail: rebecalaise@gmail.com \\ 2. Ione Celeste Jesus de Sousa, Departamento de Ciências Humanas e Filosofia, Universidade Estadual de Feira de Santana, e-mail: \\ icjs@gmail.com
}

PALAVRAS-CHAVE: História da Educação na Bahia, Historiografia, Estado da Arte.

\section{INTRODUÇÃO}

O trabalho aqui presente teve como proposta a realização de um levantamento exploratório e inicial das pesquisas no campo de história da educação produzidas nos cursos de graduação e pós - graduações de História na Bahia, no período de 1990 à 2020.A historiografia do campo da História da Educação ressalta que as décadas de 1970 e 1980 foram um período de expansão e consolidação do mesmo nas universidades brasileiras com a criação de periódicos dedicados à temática, congressos e grupos de pesquisa, conforme VIDAL \& FARIA $(2003 ; 37)$ :

A partir do fim dos anos 1960 e início dos 70, com o surgimento dos Programas de PósGraduação em Educação no país (o da PUC-Rio, em 1965, e da PUC-SP, em 1969, foram os primeiros a se constituir), e dos anos 1980, com a criação do Grupo de Trabalho "História da Educação" da Associação Nacional de Pós-Graduação e Pesquisa em Educação (ANPEd), em 1984, e do Grupo de Estudos e Pesquisas "História, Sociedade e Educação no Brasil"(HISTEDBR), em 1986, cresceu substantivamente a produção de trabalhos em História da Educação no Brasil. Ao mesmo tempo foi-se constituindo uma certa identidade, ainda que multifacetada e plural do historiador da educação. No entanto, já desde a segunda metade do século XIX, tratados sobre história da educação brasileira foram elaborados por médicos, advogados, engenheiros, religiosos, educadores e historiadores e circularam no País e no exterior. 
Existem trabalhos que se dedicam a realizar o levantamento historiográfico sobre este processo para os congressos realizados pelas sociedades acadêmicas de pesquisa que congregam os pesquisadores do campo, como a SBHE, a HISTEDBR, a ANPED. (ALVES, Claudia; VIDAL \& FARIA: 2005; CATTANI, Denise:XAVIER, Libania...) Outros balanços mais específicos sobre subcampos da História da Educação, já foram elaborados como os de VEIGA e PINTASSILGO, WARDE, NUNES. Os mais atuais são sobre a educação de negros de autoria da historiadora Surya Barros "ALGUMAS QUESTÕES ACERCA DA HISTÓRIA DA EDUCAÇÃO DA POPULAÇÃO NEGRA NO BRASIL: ESTADO DA ARTE (1989-2010)" e "HISTÓRIA DA EDUCAÇÃO DA POPULAÇÃO NEGRA: ENTRE SILENCIAMENTO" E RESISTÊNCIA e "HISTÓRIA DA EDUCAÇÃO NA REPÚBLICA: instituições, culturas escolares e trajetórias docentes" livro que reúne trabalhos de diferentes lugares do estado da Bahia que foram apresentados no IV Encontro Estadual de Ensino de História da ANPUH-BA, que ocorreu na cidade de Conceição de Coité em 2015 sediado pela UNEB ( Universidade do Estado da Bahia), e segundo os organizadores José Augusto Luz e Antonieta Miguel, permitiu conhecer o atual estado do conhecimento historiográfico na Bahia.

A importância deste tipo de produção, um levantamento da historiografia de um campo temático de investigação, não apenas para elencar títulos, mas especialmente para refletir sobre os caminhos do próprio campo, dar visibilidade à produção investigativa já existente; aos/as, pesquisadores/as; e mapear instituições e programas. Assim, o trabalho aqui se propos na construção de um apontamento sobre a historiografia da Historia da Educação, nos cursos de História existentes na Bahia e em Sergipe, é de fundamental importância por objetivar coletar dados para a construção de levantamento atualizado da mesma destacando os temas mais abordados, os períodos escolhidos e o lugar de produção dessas obras na historiografia baiana.

\section{MATERIAL E MÉTODOS OU METODOLOGIA (ou equivalente)}

A partir de uma história social da educação que privilegia a articulação entre os sujeitos da educação/escolarização e suas experiências e práticas propomos uma primeira reflexão sobre a historiografia já produzida no Campo temático da história da educação dos cursos de história baianos/sergipanos e seus sujeitos/instituições.

A metodologia da pesquisa consistiu nos seguintes procedimentos:

1) identificação dos cursos de história existentes na Bahia e em Sergipe, seu caráter e modalidades de graduação e pós-graduação;

2) Investigação da historiografia produzida em termos de campos temáticos e destaque na referente ao campo da História da Educação.

3) Levantamento sistemático desta, com uso de ficha catalográfica que registre: autor/a; tema; título; recorte temporal e espacial; sujeitos e ou instituições; conceitos e categorias chaves a partir dos uni termos/palavras chaves; aporte teórico metodológico; indicação de fontes para construção de um ementário que constara do catalogo a ser elaborado, junto com o Resumo que acompanha o texto identificado. A fonte de pesquisa básica para a confecção do catalogo foram os sites dos cursos de história existentes na Bahia/Sergipe, que já indexam a produção elaborada. 


\section{RESULTADOS E/OU DISCUSSÃO (ou Análise e discussão dos resultados)}

Das 45 produções encontradas, 42 pertencem ao levantamento realizado nos cursos de pós-graduação em História da Bahia, que se localizam cinco instituições de ensino superior (IES) no estado: três estaduais UNEB (Universidade do Estado da Bahia), UEFS (Universidade Estadual de Feira de Santana) e UESC (Universidade Estadual de Santa Cruz). E em duas federais: UFRB (Universidade Federal do Recôncavo) e a UFBA (Universidade Federal da Bahia). Essa última concentra a maioria da produção.

Dos 71 trabalhos analisados na UFS (Universidade Federal de Sergipe) só três trabalhos foram identificados como inseridos no campo da História da Educação, ambas na modalidade de mestrado acadêmico. Os três possuem o recorte temporal focado no período republicano, foram realizadas entre os anos de 2015 e 2018, sendo duas delas orientadas pelo mesmo docente, o $\operatorname{Prof}^{\circ} \operatorname{Dr}^{\circ}$ Claude Franklin Monteiro.

O interesse pela temática de analisar a produção no campo da História da Educação que vem sendo realizada nas Pós Graduações em História na Bahia e em Sergipe surgiu no processo de desenvolvimento de uma anterior atividade de levantamento da historiografia da Educação na Bahia visando apresentar painel para o VII-ENNEH (Encontro Norte Nordeste de História da Educação) que seria promovido pela SBHE, a ocorrer em novembro de 2019 nas dependências do campus UNEB- I. A coordenadora deste projeto de painel seria a professora Ione Sousa, membro do Comitê Organizador e Cientifico. A referida docente da UEFS/DCHF, era a orientadora de anterior Bolsa de Iniciação Cientifica com o projeto de pesquisa "Conflitos Políticos e a Expansão dos Prédios Escolares -1910 - 1963”. Esta bolsa anterior teve vigência durante o período de julho de 2018 até 31 de julho de 2019.A elaboração deste painel, que não foi apresentado pela supressão do Evento, já se constituia num levantamento da produção em Historia da Educação na Bahia. Quanto ao processo de pesquisa efetuado, este permitiu observar, de acordo com os dados levantados e com as as leituras de resumos realizadas, que os historiadores que produziram trabalhos no campo da História da Educação têm revisitado os "velhos objetos" sob um novo olhar. Da mesma forma têm se debruçado sobre novos objetos e novas fontes, seguindo o roteiro inaugurado pela nova história cultural desde os anos 1980. Anteriormente no sentido da expansão de novos temas e de uma olhar diferenciado para as fontes tradicionais, que a professora Clarisse Nunes, em artigo inaugural de 1992 intitulado "História da educação brasileira: novas abordagens e velhos objetos," argumentou pela pertinência que o campo de investigação da História da Educação, no Brasil se reinventasse incorporando proposições já correntes em outros campo temáticos da história:

A nossa história da educação tem primado por focalizar a escola seja sob a lente da legislação e organização escolar, seja sob a lente das demandas de escolarização da sociedade brasileira, seja sob a perspectiva pensamento pedagógico ou do ideário. Muito pouco sabemos, no entanto, sobre as suas práticas: como elas se materializavam? quais os seus efeitos? Como traduziram o movimento de modernização da sociedade, movimento este que também ajudaram a construir? Estas questões crescem em importância se considerarmos que elas operam um deslocamento de enfoque dos modelos dominantes de escolarização (a Escola Tradicional, a Escola Nova, por exemplo) para as múltiplas e diferenciadas práticas de apropriação desses modelos nas quais a ênfase da problematização recai sobre os usos diversos que os agentes escolares fazem da própria instituição escolar, sobre a prática de apropriação de práticas não escolares no espaço escolar e os múltiplos usos não escolares dos saberes pedagógicos. (NUNES, p.151, 1992). 
Especificamente sobre a Historiografia da História da Educação da Bahia e do Brasil, sua produção de modo geral, não apenas a produção realizada nos cursos de pósgraduação em História, nos estados da Bahia e Sergipe- que é o objeto dessa pesquisa, MENEZES (2016) afirma que as pesquisas em história da educação não se limitam aquelas realizadas nesse âmbito, mas o extrapolam. Estão presentes nos grupos de estudos específicos sobre a temática da educação de forma mais ampla; apresentam os resultados de suas pesquisas nos eventos nacionais e regionais. Os historiadores Antonieta Miguel e José Augusto Luz, através da análise da produção apresentada no "História da Educação na República: instituições, culturas escolares e trajetórias docentes" (depois organizado como livro pelos mesmos) argumentam que História da educação na Bahia está "em constante crescimento, extrapolando a realidade de Salvador e do Recôncavo como campos de pesquisa" (MIGUEL e LUZ, 2019, p.10).

Corroborando com esta reflexão de Miguel \& Luz acima destacada, considero importante destacar sobre produção levantada que boa parte dos trabalhos privilegiam as regiões do interior da Bahia onde os indivíduos que pesquisam residem. Um exemplo são os trabalhos de Kaliana Oliveira da Hora com investigações na Especialização (UESC) e no Mestrado (UNEB) centrados na cidade de Itabuna, onde reside. Outros locais encontrados no levantamento que elaborei foram Porto Seguro, Ilhéus, Brumado, Ubaitaba, Alagoinhas, Mutuípe, Amargosa, Feira de Santana.

Sobre as temáticas desta produção ressalto que acompanham as mudanças já propostas nos trabalhos de CATANI e FARIA FILHO (2002), VIDAL \& FARIA FILHO (2003) SOUSA (2014), que tratam sobre a Histografia da Educação produzida no âmbito nacional. Diagnostiquei o crescimento de pesquisas em relações de gênero, em educação de negros, sobre a história da profissão docente, sobre educação religiosa, sobre cultura escolar, e trabalhos voltados para o ensino superior. Contudo a temática das instituições escolares continua a ser o tema mais privilegiado pelos pesquisadores. Outro ponto que está de acordo com os levantamentos nacionais, é a escolha do recorte temporal que se concentram no período republicano. Dos 45 trabalhos, 35 têm a República como recorte temporal; apenas dois versam sobre colônia e 6 sobre o império. Duas são atemporais. A historiografia do campo indica que a grande escolha dos historiadores da História da Educação pelo período republicano deve-se a alguns fatores, sendo o principal a facilidade de acesso às fontes que estão mais organizadas e são abundantes, por ser um período mais recente, muitas delas já totalmente digitalizadas.

A maior produção de trabalhos em História da Educação ocorreu entre os anos de 2015 e 2018 e o baixo número nos anos posteriores podem ter relação direta com o contexto político atual com os diversos cortes nas pesquisas de cunho universitário, especialmente a diminuição considerável de bolsas ofertadas para as ciências humanas, e a crise em que vive o cenário educacional brasileiro.

\section{CONSIDERAÇÕES FINAIS (ou Conclusão)}

A pesquisa possibilitou através da análise do levantamento diagnosticar, delimitar e refletir que a produção de História da Educação nos cursos de pós-graduação em História na Bahia e Sergipe ainda é parca, mesmo com o crescente aumento nessa produção desde de 2015. Levando em conta a produção analisada menos de $20 \%$ da produção é centrada em história da educação. Contudo, a diversificação de temáticas e de sujeitos é a característica mais interessante e promissora. 


\section{REFERÊNCIAS}

ALVES, Cláudia Costa, (1998). Os resumos das comunicações e as possibilidades esboçadas no II Congresso Luso-Brasileiro de História da Educação. In: CATANI, Denise, SOUZA, Cynthia Pereira de (orgs.). Práticas educativas, culturas escolares, profissão docente. São Paulo: Escrituras.

BARREIRA, Luís Carlos. História e historiografia. As escritas recentes da história da educação brasileira (1971-1988). Doutorado, Faculdade de Educação, UNICAMP, 1995. CATANI, D. Bárbara. e FARIA FILHO, Luciano Mendes de. Um lugar de produção e a produção de um lugar: a história e a historiografia divulgadas no GT História da Educação da ANPED (1985-2000). Revista Brasileira de Educação, 19, 113-128, jan. /abr. 2002.

GONDRA, José G., CARVALHO, Marta M. Chagas de. Pesquisa histórica: retratos da educação no Brasil. Rio de Janeiro: UERJ, s.d.

LOPES, Eliane Marta Teixeira, (1985). História da educação ou educação pela história? Educação em Revista, Belo Horizonte, n. ${ }^{\circ}$ 1, p.8-12.

LOPES, Eliane Marta \& GALVÃO, Ana Maria. História da educação. Rio de Janeiro: DP\&A, 2001.

MIGUEL, Antonieta;Luz, José Augusto Ramos da. História da Educação na República: instituições, culturas escolares e trajetórias docentes. Curitiba: CRV,2019

MENEZES, J. M. F. de. (2016). História e historiografia da educação - a Bahia e suas conexões com os estudos regionais e nacionais. Revista HISTEDBR On-Line, 16(67), 228-237. https://doi.org/10.20396/rho.v16i67.8646120

NÓVOA, António, (1996). História da educação: percursos de uma disciplina. Análise Psicológica, Lisboa, n. ${ }^{\circ}$ 4, p. 417-434.

NUNES, Clarice, (1991). Uma história em construção. In: ANPED. Documento de discussão de balanço de gestão (mimeo).

. "A instrução pública e a primeira história sistematizada da educação brasileira". Cadernos de Pesquisa, nr. 93, maio 1995, p. 51-59.

."Ensino e historiografia da educação: problematização de uma hipótese". Revista

brasileira de educação, nr. 1, jan. abr. 1996, p. 67-79.

PERES, Eliane. BASTOS, Maria H. C. Associação Sul-rio-grandense de Pesquisadoras em História da Educação (ASPHE): a trajetória de uma rede de pesquisadores. Educação em Revista, n. 34, dez/2001, p. 121-127.

SAVIANI, Demerval. O debate teórico e metodológico no campo da história e sua importância para a pesquisa educacional. In: SAVIANI, Demerval; LOMBARDI, José C.; SANFELICE, José L. (Orgs.) História e história da educação: o debate teórico metodológico atual. Campinas: Autores Associados/HISTEDBR, 1998, p. 7-15.

SAVIANI, Demerval; LOMBARDI, José C. Grupo de Estudos e Pesquisas História, Sociedade e Educação no Brasil (HISTEDBR): histórico e situação atual. Educação em Revista, n. 34, dez/2001, p. 135-146. VEIGA, Cynthia G. e PINTASSILGO, Joaquim. Pesquisas em história da educação no Brasil e em Portugal: caminhos da polifonia. Belo Horizonte/Lisboa, 2000, 17p. Impresso.

WARDE, Mirian Jorge. Anotações para uma Historiografia da Educação Brasileira. Em Aberto, ano 3, n.23, set./out. 1984.

"Contribuição da História para a Educação". Em aberto, ano IX, nr. 47, jul. Set. 1990, p. 3-11. XAVIER, Libânea Nacif, (2001). Particularidades de um campo disciplinar em consolidação: balanço do I Congresso Brasileiro de História da Educação (RJ/2000). In: Sociedade Brasileira de História da Educação, (org.). Educação no Brasil. Campinas: SBHE \& Autores Associados. 